\title{
Youth between Labour Market and NEET - Critical Review on the Foresighted Challenges
}

\author{
Mohamed Buheji \\ Founder of the International Inspiration \\ Economy Project, Bahrain \\ E-mail: buhejim@gmail.com
}

Received: Dec. 5, 2019 Accepted: Dec. 25, 2019 Online published: Jan. 2, 2020

doi:10.5296/ijhrs.v10i1.16171ＵRL: https://doi.org/10.5296/ijhrs.v10i1.16171

\begin{abstract}
This paper critically reviews the challenges and the opportunities of youth in the labour market based on the work of Halvorsen and Hvinden (2018) and synthesis of the author on the subject. The conditions of the labour market in relevance to youth today is reviewed with a specific focus on the issue of Not in Employment, Not in Education and Not in Training NEET. Then the role of social regulations in closing youth NEET gap is investigated. The challenges of the labour market on youth today and the foresighted future are explored to see the best possible solutions.

The critical review recommends further focused comprehensive social protection system that brings in solutions that meet and close the increasing gap of the contemporary and future market demand and dynamics on youth and their economic contribution opportunities.
\end{abstract}

Keywords: youth, youth economy, labour market, youth employment, diversity, NEET, social regulation, socio-economic issues

\section{Introduction}

This paper is extracted based on the selective review of the work of Halvorsen and Hvinden (2018), which focus on studying the challenges of youth coming challenges. The paper sees the changing requirements of the labour market and its influence on youth employment and the rising rate of Not in Employment, Not in Education and Not in Training (NEET) youth.

Despite the reference of Halvorsen and Hvinden (2018) focus on the Nordic countries and their adopted policies, this paper is considered to be generic for all those practitioners and decision-makers concerned about the future stability of the labour market and the integration of youth with the environment. Buheji (2019a). 


\section{MInstitute ${ }_{\text {Mnk }}^{\text {Macrothink }}$}

The work of the author and Halvorsen and Hvinden (2018) coincides a lot in the area of the current and coming youth challenges and turbulences related to the stage of transition from school to employment. Youth have been facing new demands, that were not managed or realised properly; which led to the rise of unemployment waiting time, job insecurity, or joblessness. In the same time, the active labour market policies (ALMPs) stayed stagnant, did not change or develop. Even the incentive-based scheme released in many developed and emerging economies, or rich developing countries did not address the problem of the increase in NEET or closing the demands of the labour market.

\section{Critical Literature Review}

\subsection{The Condition of Labour Market in Relevance to Youth Today}

There are substantial dynamical changes in the labour market due to the changes in its constructs that build the socio-economic outcomes in relevance to many quality of life inputs. For example, if we examine the 'transition from education to employment' in both a decade ago and today, we would find a vast difference. With the transition from being an industrial-based economy to becoming more of a creative knowledge-based economy, the barriers for entering the European labour market has increased.

Transitions from school to employment requires more than ever today complex skills, solo management of the work, from the point of the employer; while youth require their rights in a life balance while anticipating more flexibility in their rights to education, training and employment productivity terms and conditions. Buheji (2019c).

More than ever, the labour market requires a more flexible workforce that easily adapts to the rapidly changing needs of the economy. Thus youth are expected to face new expectations and conditions to survive or succeed. Inclusion in the labour market became interrelated with the mega parallel transitions, especially with the developing of what is called today the fourth industrial revolution. This is causing more fluctuation of youth between being partly in education, or part-time paid work, or taking temporary jobs, or those taking the entire decision of financial dependency on their parents.

\subsection{The Issue of NEET}

The author and other researchers published many studies around NEET. Most of these studies focus on the causality of NEET due to the changing occupational structures and new skills requirements that prevented all the efforts of the inclusion of youth in the economic and socio-economic cycle of many countries. Buheji (2019a).

The creative, innovation-driven knowledge-based economy is classifying youth upon their capacity to deal with information as it has become the gauge of economic development. These changes in occupational terms and conditions require different social skills and mindset.

The other factor that is increasing the issue of NEET is the increase of the total periods of youth education and their willingness to take temporary or jobs. This started to delay many young people from being established. Research now shows that many of those who have been 
NEET for a long time and in early adulthood would have more potential to have unstable job prospects, earnings and well-being, Buheji (2019a).

The other challenging issue of NEET statistics is that young women are more likely to be NEETs than are young men, especially between the age of 25-29 years.

\subsection{Role of Social Regulation in Closing Youth NEET Gap}

Halvorsen and Hvinden (2018) bring in social regulation as a means, for creating change. Social regulation is a combination of the proposed regulation and financial incentives, i.e. it joins persuasion philosophy that promotes social values and welfare goals. The idea for calling of bringing in social regulations is to influence the behaviour youth and the employers in a way that would create more opportunities for interactions.

The work of Halvorsen and Hvinden (2018) give a good case study of how the Nordic countries are facilitating the transitioning youth to the labour market. The work helps to link how the current and foresighted risks on youth are essential to control the causality for NEET, starting from the type of schools' dropout until we reach the labour market exclusion practices.

The comparative study that Halvorsen and Hvinden (2018) for the social regulations models of the OECD countries in relevant to specifically youth labour market outsiderness, help to appreciate the proposed approaches later presented in Chapter Six of this reference book. The new suggested approaches promote youth inclusion in the labour market. The Nordic authors show based on this the current disability in the Nordic welfare system that needs to be addressed.

Similar to the Nordic experience, many countries are still challenged with the inclusion of the early school leavers, youth with disabilities and the minority ethnic youth to the labour market. Therefore, Halvorsen and Hvinden (2018) call for unified social networks, recruitment strategies that protect the vulnerable youth.

Some youth may have to move back to their parents' home while waiting for new employment opportunities (Gökşen et al., 2017). Lack of affordable and relevant accommodation affects geographic mobility of young adults and consequently the ability to seek higher education and find paid work. Similarly, a segregated housing market is likely to be associated with systematic differences in appreciation of education and school performance depending on social class (parents' education, income and occupation) and differences in children's language skills between kindergartens, schools and after-school programmes. Buheji (2018a).

\subsection{Challenges of the Labour Market on Youth}

The complexity of the transitions in the labour market is highly associated today with the capacity of youth conclusion in relevance to labour market new segmentation and early exit, Buheji (2017).

The dynamics of the labour market surpass the speed and the frequency of the educational 
reforms which are trying to find the most suitable formula between theoretical education and vocational training (including the availability of apprenticeship schemes). The challenge now whether the learning service providers would be able to deliver more 'tailor-made' educational trajectories taking into account the talents and interests.

As the number of jobs available for unskilled workers is declining, students with incomplete suitable education would have been lacking the employment opportunities and risk becoming locked on getting a suitable paid job. Buheji (2017).

The challenge of the labour market is the immigrant youth who are finding difficulty in suitable education or recognised professions. This also brings in the issue of the need for more transparent diversity policies that take into account the diverse backgrounds of ethnicity, religious and different levels of disability. Buheji (2018a).

\subsection{Consequences of Youth Exclusion from the Labour Market}

Studies show that unless youth establish themselves in the labour market, the size of the next generation's labour force will decrease, and fewer people will contribute to the economy, be economically independent and able to pay taxes. This would increase the dependency ratio, and this would be influenced by demographic ageing. Halvorsen and Hvinden (2018), Buheji and Ahmed (2019).

Without the inclusion of youth in the social welfare system, intergenerational solidarity would be weak and also youth would become too dependent on social security. This would increase relative poverty among youth, Buheji (2019b).

\section{Discussion and Concluding Remarks}

The reviewed work of Halvorsen and Hvinden (2018) have shown that youth unemployment might increase unless effective social and socio-economic and educational reforms dare made to reduce the 'scarring effect'. The experience of NEET not only reduces the youth's employability, but their future capacity for a differentiated contribution. Buheji (2017).

The solution addressed by Halvorsen and Hvinden (2018) regarding enabling the youth of ethnic minorities or with disabilities to find and retain a suitable job, as giving more legal possibilities for employers, providing of financial incentives and structures for employers to build a corporate culture that promotes diversity in the workforce. Therefore, one of the best contributions of this reviewed book is how to increase the youth labour market participation through balancing between income maintenance subsystem and setting measures that influence employers' behaviour. The wage subsidies, for example, to employers (provision on the supply side) may resemble opportunities to combine social security and part-time work.

The social protection system proposed by Halvorsen and Hvinden (2018) link actors together across time and space to foster quality of life and opportunities for better youth participation in reproducing better socio-economic interaction patterns. Buheji (2019c. 2019d).

In social protection systems, as suggested in the work of Halvorsen and Hvinden (2018) major social institutions such as family, organised civil society and the private sector need to 


\section{Macrothink

work together to meet the transition of youth to market demands, to avoid total dependence on the welfare state. Governments and decision-makers should avoid the risks of ignoring factors or mechanisms that influence the transitions between education and the labour market for youth. All social actors need to align their efforts to smoothen the transitions between education and the labour market of youth. Therefore, this paper calls for further research to explore and then improve the in comprehensive up to date social protection system that brings in practical possibilities towards achieving a smooth transition of youth towards the contemporary and the immediate foresighted turbulent economic environment.

\section{References}

Buheji, M. (2017). Forward- 'Youth Economy and Utilisation of Lost Opportunities', International Journal of Youth Economy, 1(2), 1-2

Buheji, M. (2018b). Handbook of Youth Economy, AuthorHouse, UK.

Buheji, M. (2019a). Discovering Pathways for Eliminating NEET and Youth Future Type of Poverty. International Journal of Human Resource Studies, 9(3), 320-340.

Buheji, M. (2019b) Youth Unemployment Mitigation Labs - An Empathetic Approach for Complex Socio-Economic Problem. American Journal of Economics, 9(3), 93-105.

Buheji, M. (2019c). In Pursuit of a Youth Life-Purposefulness Program. International Journal of Human Resource Studies, 9(4), 69-76.

Buheji, M. (2019d) Prospects of Youth Quality of Life. International Journal of Youth Economy, 3(2), I-III.

Buheji, M., \& Ahmed, D. (2019) The Youthineering- 'New Perspectives on Youth Economy’ (Edited Book), AuthorHouse Publishing, UK. (Published in Oct, 2019).

Buheji, M. (2018a). Foreword - 'Youth Role in Transforming Change towards a better World'. International Journal of Youth Economy, 2(2), I-II.

Halvorsen, R., \& Hvinden, B. (2018). Youth, Diversity and Employment Comparative Perspectives on Labour Market Policies. E-Elgar, UK.

\section{Copyright Disclaimer}

Copyright for this article is retained by the author(s), with first publication rights granted to the journal.

This is an open-access article distributed under the terms and conditions of the Creative Commons Attribution license (http://creativecommons.org/licenses/by/4.0/). 